\title{
Introduction: A Gender and Reparations Taxonomy
}

\author{
Ruth Rubio-Marín
}

In recent years, work in a variety of disciplines has sought to illuminate and highlight women's experience of conflict and authoritarianism. UN Security Council Resolution 1325 on women, peace, and security ${ }^{1}$ reflects this when addressing the need to recognize the impact of armed conflict on women and girls, the role of women in peacebuilding, and the gender dimensions of peace processes and conflict resolution. The serious and pervasive nature of genderbased violence in conflict, especially sexual and reproductive violence, has also been increasingly recognized under international criminal law. ${ }^{2}$ Relevant discussions about how other transitional justice measures, including truthtelling mechanisms, can do better justice to women have followed. ${ }^{3}$ It comes as no surprise, then, that the time is ripe to raise the question of how reparations programs for mass human rights violations can be designed in ways intended to redress women more fairly and efficiently. ${ }^{4}$

The fact that reparations programs are becoming an increasingly frequent feature of transitional and post-conflict processes renders the topic of this book

${ }^{1}$ United Nations Security Council, Resolution 1325, S/RES/1325 (2000), October 31, 2000.

${ }^{2}$ Proof of this is the Rome Statute of the International Criminal Court, which adopts "rape, sexual slavery, enforced prostitution, forced pregnancy, enforced sterilization, or any other form of sexual violence of comparable gravity" as part of its definition of crimes against humanity and war crimes. See the Rome Statute of the International Criminal Court, Arts. 7 and 8.

3 Debra L. DeLaet, "Gender Justice: A Gendered Assessment of Truth-Telling Mechanisms," in Telling the Truths: Truth Telling and Peace Building in Post-Conflict Societies, ed. Tristan Anne Borer (Notre Dame, IN: University of Notre Dame Press, 2006), 151-181; World Bank, "Gender, Justice, and Truth Commissions," Washington, DC: World Bank, June 2006; Vasuki Nesiah et al., "Truth Commissions and Gender: Principle, Policies and Procedures," (New York: ICTJ, 2006); Fionnuala Ni Aoláin and Catherine Turner, "Gender, Truth and Transition," UCLA Women's Law Journal 16 (2007): 229-279.

4 International civil society has started to echo this concern: in March 2007, the Nairobi Declaration on Women's and Girls' Right to a Remedy and Reparation was adopted. See http://www. womensrightscoalition.org/site/reparation/signature_en.php. 
only more relevant and urgent. Indeed, there is a growing conviction that doing justice in transitional scenarios requires not only doing something against the perpetrators, but also doing something specifically for victims. ${ }^{5}$ This trend is confirmed by the recommendations of several truth commissions, and by the jurisprudence of both national and international human rights bodies, including the European Court of Human Rights and the Inter-American Court of Human Rights. Nations as diverse as Argentina, Chile, Brazil, South Africa, Guatemala, Peru, and Morocco are examples of countries that have thought of reparations initiatives as an important component of their package of transitional justice measures. The UN has also supported this evolution toward enhancing the importance of the reparative venue and giving victims adequate recognition and redress: in 2005, the General Assembly approved the Basic Principles and Guidelines on the Right to a Remedy and Reparation for Victims of Gross Violations of International Human Rights Law and Serious Violations of International Humanitarian Law, ${ }^{6}$ and just recently the High Commissioner for Human Rights has produced a tool on reparations programs as part of its series of Rule-of-Law Tools for Post-Conflict States. ${ }^{7}$ The latter document is intended, among other things, to guide state practice on how to render the Basic Principles operative.

The moves toward "engendering transitional justice" and pushing forward the reparations agenda have thus far progressed in parallel and without meaningful encounters. For the most part, reparations initiatives around the world have to this day failed to raise systematically the question of how to incorporate women's specific needs and concerns. This is striking in view of the fact that a significant number of victims of authoritarianism and conflict are women who are known to experience both phenomena in distinct ways. Similarly, it is common knowledge that in most cases women play a crucial role in the follow-up of violence - searching for victims or their remains, trying to reconstitute families and communities, carrying on the tasks of memory, and

5 See Pablo de Greiff, "Introduction," in The Handbook of Reparations, ed. Pablo de Greiff (Oxford: Oxford University Press, 2006), 1-18 [The Handbook, hereafter].

${ }^{6}$ Basic Principles and Guidelines on the Right to a Remedy and Reparation for Victims of Gross Violations of International Human Rights Law and Serious Violations of International Humanitarian Law, A/RES/60/147, March 21, 2006 [Basic Principles, hereafter]. See also the UN Secretary General's 2004 report, The Rule of Law and Transitional Justice in Conflict and Post-Conflict Societies, S/2004/616, August 23, 2004; Updated Set of Principles for the Protection and Promotion of Human Rights through Action to Combat Impunity, E/CN.4/2005/102/Add.1, February 8, 2005; Diane Orentlicher, Independent Study on Best Practices, Including Recommendations, to Assist States in Strengthening Their Domestic Capacity to Combat All Aspects of Impunity, E/CN.4/2004/88, February 27, 2004; and Report of the Independent Expert to Update the Set of Principles to Combat Impunity, E/CN.4/2005/102, February 18, 2005.

7 Available at http://www.ohchr.org/Documents/Publications/ReparationsProgrammes.pdf. 
demanding justice. Despite all of this, reparations programs have not been designed with an explicit gender dimension. And yet, there are few reasons to believe that so-called "gender-neutral" reparations programs equally facilitate the achievement of the underlying goals of reparations programs, including recognition, civic trust, and social solidarity for men and women. ${ }^{8}$ True, the goals of a reparations program are to provide a measure of justice, albeit imperfect, to victims; but reparations are also intimately tied to building a just and peaceful foundation for a transitioning society. A program that fails to provide redress or justice to women in effect weakens the link between the goals of reparations and their contribution to the establishment of a democratic state.

This book seeks to lay the foundations for a gender-sensitive analysis of reparations programs that would increase their effectiveness as redress measures available to female victims and their families. The analysis is also intended to maximize the transformative potential of reparations programs and thus their capacity to help advance toward more inclusive and egalitarian democracies (potential and capacities that it is important not to overestimate). The book is the result of an ambitious three-year research project undertaken by the International Center for Transitional Justice (ICTJ). Besides learning what reparations programs to date in fact have done with respect to gender issues, the project took to heart the task of starting to articulate what future programs ought to do if they aspire to do justice to female victims in transitional or postconflict situations, and thus of articulating the normative goals of reparations programs with respect to gender issues. This dual empirical and normative perspective characteristic of ICTJ research projects would, it was hoped, make it possible to identify best practices and, more importantly, to propose innovative approaches to the integration of a gender perspective into the design and implementation of reparations programs. It would ultimately also serve to test and to illustrate the project's underlying hypothesis, namely, that a gender perspective would make a difference in the field of reparations.

The first task was to make up for the dearth of factual information on the different needs of men and women vis-à-vis reparations. We tried to do this by compiling case studies that provided detailed accounts of how six countries Peru, Guatemala, Sierra Leone, Rwanda, Timor-Leste, and South Africa have dealt or failed to deal with gender issues in their discussions about how to repair victims. ${ }^{9}$ Then came the challenge of thinking about the topic both

${ }^{8}$ These are some of the goals that are attributed to reparations programs by Pablo de Greiff in his "Justice and Reparations," in The Handbook, 451-477.

9 See the six case studies in Ruth Rubio-Marín, ed., What Happened to the Women? Gender and Reparations for Human Rights Violations (New York: Social Science Research Council, 2006) [What Happened, hereafter]. 
thematically and normatively, which is what the present book attempts to do benefiting from the empirical information gathered in the previous volume.

Before entering into a brief discussion of the contents and structure of this collection, two preliminary comments are called for. The first one has to do with the prevailing emphasis that the book places on women. Of course, "gender" need not refer to women alone. However, given present conditions, concerns about gender and gender sensitivity in this and most other contexts in which justice issues arise refer to the disparities and inequities in access, power, opportunities, and rights experienced by women across a wide spectrum of spheres. Although we have followed this well-established use of the term gender in this book, most authors have come up with insight on how patterns and notions of masculinity can interfere either with the assessment of the harms that men are subject to during times of repression and conflict, or with their possibilities for redress, thereby underscoring the need to conceptually broaden the gender and reparations agenda so as to include men and boys.

The second comment has to do with the overwhelming (if not exclusive) focus on reparations programs as opposed to other modalities such as judicial reparations procedures, which typically operate on a case-by-case basis and which individualize compensation measures, tailoring each of them so as to compensate in proportion to the harm suffered by each individual victim. There are general and gender-specific reasons for our focus on programs rather than court procedures. In general, international practice seems to suggest that more and more countries are coming to the realization that when reparations are owed to a large universe of victims resulting from widespread and systematic use of violence, administrative programs may be better suited to the task. In part, this choice is motivated by reasons of expediency. However, there may be another important reason to favor massive programs: in compensating everyone within the same category of violation in roughly the same way, rather than adjusting the payment in accordance with calculations of individual harms, the programs avoid a potentially inegalitarian message and consequent divisions among victims. ${ }^{10}$ Also, in providing redress for the violation of rights rather than compensating the loss of wealth, the programs indicate their nature as rights-promoting and rights-enhancing measures. ${ }^{11}$ Reparations then become mainly a form of recognizing victims as citizens and equal rights bearers.

${ }^{10}$ See de Greiff, "Justice and Reparations," $45^{8}$.

${ }^{11}$ For an elaboration of the reasons why in transitional situations reparations programs may be a better response than individual case-by-case judicial procedures, see de Greiff, "Justice and Reparations"; Pablo de Greiff and Marieke Wierda, "The Trust Fund for Victims of the International Criminal Court: Between Possibilities and Constraints," in Out of the Ashes: Reparation for Victims of Gross and Systematic Human Rights Violations, ed. Marc Bossuyt, Paul Lemmens, Koen de Feyter, and Stephan Parmentier (Antwerp: Intersentia, 2005) [Out of 
If all of the above is true in general, I have argued elsewhere that there are also gender-specific reasons to favor large-scale reparations programs that place the emphasis on the recognition of victims as opposed to judicial reparations seeking compensation in proportion to harm. ${ }^{12}$ Maybe the most important one is that reparations programs can obviate some of the difficulties and costs associated with litigation, including high expenses, the need to gather evidence (which in some cases may be unavailable), the pain associated with crossexamination, and the lack of confidence on the part of victims in judicial systems $^{13}$ - difficulties that may have a particularly strong disparate and negative effect on women. Overrepresented among the poor, the illiterate, those with little information, those facing language barriers, and those overburdened with family-related obligations that make traveling long distances a difficult task, women may find it particularly difficult to access the court system. Also, the large underreporting of gender crimes even in "normal times" speaks of the challenges women face in most societies in trying to make use of criminal processes that can so often result in their further victimization.

\section{STRUCTURE AND CONTENTS OF THE BOOK}

The first two chapters of the volume were conceived as the normative framework of the project. Margaret Walker's "Gender and Violence in Focus: A Background for Gender Justice in Reparations" provides an overview and analysis of the nature and varieties of violence and harms that are known to affect women in contexts of armed conflict and political repression. The chapter examines both the forms of violence that affect women and the gendered character of these forms of violence. Current research establishes that violence and harms suffered by women in these contexts are many and are often linked in complex ways. The links create destructive synergies of loss and suffering: violence inflicted on women harms women; some harms expose women to further violence and additional harms; and serious, even life-altering

the Ashes, hereafter]; Debra Satz, "Countering the Wrongs of the Past: The Role of Compensation," in Reparations: Interdisciplinary Inquiries, ed. Jon Miller and Rahul Kumar (New York: Oxford University Press, 2007); and Naomi Roht-Arriaza, "Reparations in the Aftermath of Repression and Mass Violence," in My Neighbor, My Enemy: Justice and Community in the Aftermath of Mass Atrocity, ed. Eric Stover and Harvey M. Weinstein (Cambridge: Cambridge University Press, 2004).

${ }^{12}$ See Ruth Rubio-Marín and Pablo de Greiff, "Women and Reparations," International Journal of Transitional Justice 1, no. 3 (2007): 317-337.

13 See de Greiff, "Justice and Reparations," and Heidy Rombouts, Pietro Sardaro, and Stef Vandeginste, "The Right to Reparation for Victims of Gross and Systematic Violations of Human Rights," in Out of the Ashes, 488. 
or life-threatening harms result from forms of violence and repression that do not target primarily women but that nevertheless affect them decisively. The chapter begins with the assumption that certain forms of coercion and violence against women are recurrent to a greater or lesser extent in many contemporary societies. It develops a critical and cautionary perspective, however, on the idea that violence in conflict is best seen as being "on a continuum" with everyday violence against women. Though a unifying explanation of violence against women serves important purposes for policy analysis and designing futureoriented preventive measures, it does not capture adequately the experience of catastrophic and life-changing violence many women experience in conflict situations. A victim-oriented perspective is crucial for understanding the meaning and consequences of violence with an eye to reparations. Walker articulates seven factors that emerge as salient in conceptualizing and understanding the violence and harm women suffer: (1) some of the forms of violence that target women are status-defining male exchanges; (2) violence is often used as a threat and punishment for women's gender transgression in political contexts; (3) many of the forms that violence against women takes target women's sexuality or reproductive capacity; (4) violence against women also takes the shape of women's property being appropriated or destroyed; (5) women's access to and their roles in creating social capital are frequently damaged by violence; (6) women are exposed to special and intense forms of shame and exclusion after they experience violence; and (7) women are frequently blocked from being, or insecure or socially discredited as, testifiers to violence to themselves. The chapter proposes the nonexclusive categories of gender-normative violence, sex-, reproduction-, or care-specific violence, gender-skewed violence, and gendermultiplied violence as constituting an analytic grid for tracking different ways in which harms befall women "because they are women," sexually, psychologically, socially, and politically. These categories are rooted in research on actual instances of conflict and repression, and the idea is that they can help us ask the right questions about how women are harmed.

The aim of Chapter 2, "The Gender of Reparations in Transitional Societies," is to flesh out the potential of large-scale reparations programs in transitional democracies for recognizing and redressing women victims of human rights abuses. It also provides insight about the transformative potential of reparations, namely, the potential to subvert, instead of reinforce, preexisting structural gender inequalities and thereby to contribute, however minimally, to the consolidation of more inclusive democratic regimes. ${ }^{14}$ The chapter

${ }^{14}$ For the concept of transformative reparations, see Ruth Rubio-Marín, "Gender and Collective Reparations in the Aftermath of Conflict and Political Repression," in The Politics of Reconciliation in Multicultural Societies, ed. Will Kymlicka and Bashir Bashir (Oxford: Oxford University Press, 2008), reproduced at the end of this volume. 
starts by developing a normative framework for conceptualizing reparations, one that sets the main aim of reparations to be to give victims due recognition as citizens, something which, I argue, requires all of the following: the recognition of the wrongful violations of victims' rights; the acknowledgment of state responsibility for such violations; the recognition of harms ensuing from the violations; and the attempt to help victims cope with the effects of harms in their lives and to subvert, however minimally, the structures of subordination that might have led to the violations of their rights in the first place. The chapter then spells out what "engendering reparations" might mean in the light of these requirements. In summary, it means: first, avoiding formal gender discrimination in the design and implementation of such programs; second, looking for ways of ensuring that patriarchal norms and sexist standards and systems of values do not leak into reparations; and, third, exploring ways to optimize the (admittedly modest) transformative potential of reparations programs so that they serve to advance toward the ideal of a society altogether free of gender subordination. I try to show that taking all of this into account has an impact on how reparations programs are designed and implemented. Specifically, it affects the selection of the crimes or violations for which there will be reparations, ensuring, for example, that crimes that affect predominantly women are not left out of the list of those that trigger access to reparations programs; the definition of the notion of "beneficiary," which should reflect that violations of rights may affect male and female victims disparately, and that generally these violations affect families and communities and not only individuals; and the design of the packet of possible benefits in favor of those that will best reach women and address the multifaceted harms they experience and, to the extent possible, help women move beyond the socioeconomic status they held before the violations.

Following these two chapters is a set focusing on specific topics that are of particular importance for the issue at hand. Chapter 3 is devoted to the reparation of sexual and reproductive violence. In spite of systematic underreporting, it is well documented that both under repressive regimes and in large-scale civil conflict women and girls are often subject to many forms of sexual and reproductive abuses, including rape (sometimes mass and multiple), sexual amputations, forced prostitution, sexual slavery, forced unions, forced impregnations, forced abortions and sterilization, and other forms of sexual denigration. Men and boys are sometimes subject to similar forms of abuse, although in view of widespread cultural prejudices that "feminize" male victims of sexual violence, the underreporting in such cases is even more severe. Recent (implemented or at least recommended) reparations programs and measures, such as those in Peru, Guatemala, Rwanda, Sierra Leone, Timor-Leste, and Morocco, have reacted to the widespread use of sexual and 
reproductive violence and explicitly include sexual violence among the violations that entitle victims to reparations. In this chapter, Colleen Duggan and Ruth Jacobson address the challenges and possibilities of repairing victims of the many forms of sexual and reproductive violence, providing the most comprehensive overview of the forms of reparations that have been either implemented or recommended in the past and identifying best practices and suggesting possible innovations in the field. The challenges of coming up with adequate reparations measures for victims of sexual and reproductive violence include taking into account the variety of harms that these violations can produce, such as loss of status, communal ostracism, material destitution, contraction of sexually transmitted diseases, other harms to victims' reproductive and mental health, and the bearing and raising of unwanted children. Special difficulties for reparation come from those harms that follow not directly from the violation itself but from the reaction to the violation on the part of the spouse, extended family, or community (such as harm to the person's social status, impossibility of remarrying, repudiation by the husband and other family and community members, etc.), all of which suggest the need to come up with innovative ways to deal with reparations targeting both the individual and her environment while being careful not to reinforce sexual stereotyping or entrench sexual bias. The fact that sexual violence is the only crime for which victims themselves are often blamed is only one of the reasons that repairing this kind of violation is a particularly daunting enterprise.

It is well documented that both boys and girls are subject to various forms of abuse, including illegal detention (together with their mothers), forced recruitment, abduction and forced removal from their families, sexual abuse, sexual and domestic labor, slavery, forced marriage, and amputations, among others. Children also bear some of the most serious consequences of violations committed against their parents, such as executions or illegal detention, which can result in upbringing in an orphanage or a single- or child-headed household. Gender seems to play a significant role in the type of abuse that girls and boys more commonly experience, with girls being more often subject to sexual violence, sexual and domestic labor, and forms of slavery, and boys to forceful recruitment for combat. Also, violations affect boys and girls in gender-specific ways. Finally, given that in many societies women are the main caretakers of minors, the differential impact on whether children become beneficiaries of reparations measures on women is undeniable. All of this explains the importance in a volume such as this one of Dyan Mazurana and Khristopher Carlson's Chapter 4, "Reparations as a Means for Recognizing and Addressing Crimes and Grave Rights Violations against Girls and Boys during Situations of Armed Conflict and under Authoritarian and Dictatorial 
Regimes." Their study classifies the forms of violations and harms that children and youth experience most typically in times of political turmoil as a result of violent acts that target them or their parents. It then looks systematically at the experiences, possibilities, and challenges around repairing children for the harms they endure, placing the emphasis on the need to consult them and include their voices in reparations processes and to draft programs that enhance the visibility of children as rights bearers and not only dependent family members.

Whereas many of the forms of violence committed under dictatorial regimes and during large-scale ethnic and civil strife target men for their political activities, family members - particularly in societies predominantly organized around the family structure embracing the breadwinner model - are not only severely impacted by the violations committed against men, but also sometimes directly targeted for abuse because of their status, precisely as relatives of those who will become the "primary" victims. In either case, parents, partners, spouses, and children of the disappeared, executed, or detained persons are often left emotionally desolate and economically destitute. This is especially true of partners and spouses who are left with the entire burden of raising a family without a breadwinner, often in societies where women lack incomegenerating skills, have little education, and may even be stigmatized for their involvement in activities outside the home. Ironically, these are precisely the women who, in most experiences, lead the fight for justice and truth about their loved ones, frequently relegating reparations claims for their own suffering and hardship to the bottom of their list of claims. In Chapter 5, "Repairing Family Members: Gross Human Rights Violations and Communities of Harm," I, along with Clara Sandoval and Catalina Díaz, address the challenges, possibilities, and experiences of repairing the family members of victims of grave violations of human rights. The chapter is ambitious in its scope as it tries to provide a comprehensive account as well as a critical analysis of how the subject matter has been treated under the case law of the European Court of Human Rights and the Inter-American Court of Human Rights, and by national reparations programs. Among other things, the article underscores the importance of departing from a succession paradigm, according to which family members will receive reparations only if their loved ones have died or disappeared, in favor of one that recognizes the need to repair next of kin in their own right for the moral and material harm they experience as a result of the violations.

Chapters 6 and 7 shift the focus from forms of victimization and categories of victims and beneficiaries to forms or modalities of reparations. In Chapter 6, “Tort Theory, Microfinance, and Gender Equality Convergent in Pecuniary 
Reparations," Anita Bernstein uses tort theory as a framework to underscore the importance of providing women material redress through reparations. Doing so is important for several reasons, including the fact that by law, custom, and religion women often do not enjoy control over property and wealth comparable to men of similar class position. Also, as is well known, violent upheavals that disrupt and transform traditional divisions of labor, power, and ownership, or that involve displacement and geographical relocation, often result in dramatic and inequitable economic losses for women, or in women being unable to assert rights to property. Official statistics used to define policies of reconstruction may ignore households run de facto by women when husbands are absent or missing. With the current long-delayed and still not fully effective focus on sexual violence toward women in political conflict, there is the possibility that women's losses of livelihood, land, wealth, and economic assets or the economic effects of violations on women's lives may be eclipsed. Hence, placing the question of women's material well-being to the fore when discussing reparations is important. More concretely, Bernstein's chapter explores the possibility of giving victims shares in microfinance institutions as a promising kind of material reparations benefit. It discusses how such an alternative might encourage development in regions that are too poor to be able to dispense large payments to victims of human rights abuses. It also analyzes how, by encouraging victims' agency and security, reparations through microfinance can be especially promising for women and help them improve their status.

Brandon Hamber and Ingrid Palmary's Chapter 7, "Gender, Memorialization, and Symbolic Reparations," takes us from the realm of the material to that of the symbolic. Whereas symbolic reparations measures are becoming an increasingly common feature in reparations programs (including memorialization activities, museums, naming of streets and public activities, monuments, official apologies, etc.), there has been virtually no discussion as to whether female and male victims have gained equal/proportional symbolic recognition through reparations schemes. Nor has it been discussed whether there may be good reasons to believe that male and female victims require different forms of symbolic redress, including modalities of apologies, or are differently engaged by memorialization attempts that are interactive in nature. This chapter explores the theoretical question of what engendering memorialization and symbolic reparations projects can entail. It argues that this venture requires including women in the traditional forms of representation and symbolic recognition while at the same time changing those traditional forms in ways that have the capacity to reach and be meaningful to women. More concretely, the chapter makes suggestions as to how symbolic reparations could make a 
more substantial contribution to promoting gender justice by incorporating sufficiently complex and rich notions of masculinity and femininity.

The book closes with a chapter on gender and collective reparations ${ }^{15}$ that tries to shed some light on the multifaceted and increasingly popular notion of collective reparations and to address the possibilities that this notion opens to rendering reparations programs more gender sensitive. Because virtually everywhere women are indispensable to, and dependent on, the maintenance of the daily order of communal life, both materially and socially, the creation or reconstruction of social tissue, collective resources, and communal institutions that are often severely damaged during conflict and political repression may be essential to the normalization of their lives and the sustainability of their existence. The concept of collective reparations invites a geographical or regional approach to reparations and has clear synergies with the development and reconstruction agendas. The chapter explores ways in which collective reparations can also be linked with feminist agendas. Drawing from Walker's opening piece in this book, the chapter argues that much of the violence women experience under authoritarianism and during conflict affects them collectively by reinforcing gender meanings that are detrimental to women. More importantly, it examines whether collective reparations can stimulate reforms aimed at nonrepetition, that is, reforms that seek to guarantee not only that victims will not be victimized again, but also that no new victims will be generated. Although victims should definitely not feel under any obligation to become sacrificial lambs, some may draw a sense of satisfaction from knowing that with their lives and suffering they contributed, however modestly, to the better lives of future generations of women.

\section{GENDER AND A TAXONOMY OF REPARATIONS PROGRAMS}

Pablo de Greiff's groundbreaking book on reparations offers a taxonomy of reparations efforts organized around the basic challenges faced whenever such programs have been undertaken. Drawing from some of the lessons learned through our research, I now want to see how such a taxonomy can be assessed (in terms of the relevance and adequacy of the chosen categories) from a gender perspective. De Greiff's taxonomy refers to the following categories: scope, completeness, comprehensiveness, complexity, internal and external integrity or coherence, finality, and munificence ${ }^{16}$ Based on our work in this project, I would like to propose two additional categories, one to designate a reparations

15 Rubio-Marín, "Gender and Collective Reparations," reproduced at the end of this volume.

${ }^{16}$ de Greiff, "Introduction," 6-13. 
program's potential to transform social relations - "transformative potential" and one to designate the degree to which a reparations program has been designed and implemented with the participation of relevant stakeholders, including, of course, women - "openness."

By the "scope" of a program, de Greiff refers to the total number of beneficiaries it covers. But, as he rightly argues, since that is an absolute number and its correlation with the total number of potential beneficiaries is not clear, there is not much that can be said in abstract about the virtues of a program having a greater or smaller scope. ${ }^{17}$ The more relevant categories are those related to the ability of the program to cover, at the limit, the whole universe of potential beneficiaries ("completeness"), something that depends, crucially, on the selection of the crimes and harms that lead to reparations ("comprehensiveness"), to the evidentiary standards required for victims to qualify, and to the outreach efforts undertaken to publicize the existence of the program and render it accessible to victims. ${ }^{18}$

Much of the difference that a gender perspective can make when thinking about reparations has to do with these two categories, completeness and comprehensiveness. Leaving out of the program the worst forms of violence with a disparate impact on women and girls (such as sexual and reproductive violence) is a sure path to failure in terms of maximizing the contribution that reparations initiatives can make to reestablishing female victims' citizenship status. The same applies to endorsing a narrow definition of beneficiaries that does not take into account the harms caused by the violations to the family members of victims of political violence or the diminution of communal resources on which women disparately depend for their daily existence. The trend we observe in recent reparations initiatives toward embracing collective reparations together with individual reparations is therefore to be celebrated, as is the incipient (and still inconsistent) trend to recognize family members as victims in their own right and to include sexual and reproductive violence in the list of violations.

This said, probably the greatest obstacle for victimized women to access reparations has to do with procedural hurdles (closed lists, short application deadlines, territorially centralized procedures, high evidentiary standards, lack of confidentiality, inadequate payment mechanisms) as well as with weak outreach and dissemination policies. True, reparations programs usually fare well on these criteria compared to other reparations venues, especially courts. But this depends on explicit efforts to maximize this potential.

${ }^{18}$ Ibid., 6-10. 
In this regard, certain recent and innovative approaches deserve to be highlighted. Among them are several initiatives of Timor-Leste's Commission for Reception, Truth and Reconciliation, which, in view of the severe impact of violence on women, decided to dedicate $50 \%$ of the funds allocated for reparations to women, in the hope that this would push the follow-up body in charge of implementing the recommendations to create strong gender policies. ${ }^{19}$ The commission's reparations program (which, unfortunately, has not been implemented as of yet) would also allow women to qualify for benefits under multiple criteria, so that women who suffered sexual violence or had a child from rape could be seen as receiving reparations for other harms and in this way escape stigmatization. The program would also provide collective reparations to communities, making gender balance of beneficiaries a condition for supporting such programs. It would also link the distribution of benefits to qualifying children to the provision of services to their mothers as a way to encourage women to think about themselves, specifically offering services to women in the same place they have to visit to get the scholarship stipends for their children. Finally, Timor-Leste's commission recommended keeping its list open for two years after the closing of operations to ensure the completeness of its reparations policy.

The "complexity" of a reparations program refers to the diversity of benefits that it distributes. ${ }^{20}$ Whereas very simple programs limit themselves to the distribution of payments, the evolution toward increasingly complex programs is shown by the fact that reparations programs now often incorporate together with payments - health, education, and housing services and symbolic measures of redress, often addressed at both individuals and collectivities. Reparations programs best accomplish one of their main goals - to provide recognition to victims - if they reflect awareness of how the different types of violations affect victims, and if they craft their benefits accordingly, so as to help victims move forward with their lives in concrete ways. Given that the effects of violence are often gendered, complexity brings with it the possibility of targeting benefits flexibly so as to respond to women's specific needs more closely. For instance, sexual violence has multifaceted effects on women's lives, and it is not clear that the payment of compensation money, important as it may be, can by itself provide adequate reparation. ${ }^{21}$ Hamber and Palmary's

19 See Galuh Wandita, Karen Campbell-Nelson, and Manuela Leong Pereira, "Learning to Engender Reparations in Timor-Leste: Reaching Out to Female Victims," in What Happened, $284-334$.

20 de Greiff, "Introduction," 10.

${ }^{21}$ See Colleen Duggan and Adila Abusharaf, "Reparations of Sexual Violence in Democratic Transitions: In Search of Gender Justice," in The Handbook, and Duggan and Jacobson, in this volume. 
chapter in this volume illustrates this point with the story of the so-called "comfort women," women who were exploited sexually by the Japanese army during the second world war and who have since always insisted on the importance of monetary payments being accompanied by the proper form of apology. ${ }^{22}$ More generally, although including compensation payments in a reparations program may be essential to enhance women's economic independence, relying exclusively on monetary payments may prove inadequate reparation for a variety of reasons, including the possibility that the money will end up in men's hands and the fact that, when asked about reparations, women tend to prioritize the provision of services. ${ }^{23}$ Mazurana and Carlson express similar skepticism in their chapter about relying on monetary compensation as the main reparation measure when the intended beneficiaries are boys and girls.

"Integrity" (or "coherence") is a category that has both an internal and an external dimension. Whereas "internal coherence" refers to the relationship between the different types of benefits a program distributes and is achieved when the different benefits support each other in the achievement of the underlying aims of the program, "external coherence" expresses the requirement that the reparations efforts be designed in such a way as to be closely connected with other transitional justice mechanisms such as criminal justice, truth-telling, and institutional reform measures. According to de Greiff, coherence increases the likelihood that the different transitional efforts will satisfy the expectations of citizens. As he rightly points out, reparations without truth or justice may be perceived as a state attempt to buy the silence of victims and their families. ${ }^{24}$ In real-life scenarios, when we talk about families of victims, we are often talking about mothers and widows of the politically detained, executed, or disappeared. These women take it as their primordial task to vindicate their loved ones via truth and justice measures, and thus for many of them, compensation in the absence of other efforts to elucidate the fate and vindicate the lives of their loved ones simply will not be an option.

External coherence is also most relevant for women in another regard, especially when applied in a broad sense to include not only coherence between the measures of transitional justice, but also coherence between justice measures and all those that form the entire package of democratization measures. To see this, it is important to bear in mind that women are often subject to multiple and standard forms of abuse and exploitation before, during, and after the conflict, and that these abuses are usually committed with almost total

${ }^{22}$ See Hamber and Palmary, in this volume.

23 See Ruth Rubio-Marín, "Introduction," in What Happened, 20-47, and Rubio-Marín, in this volume, Chapter 2.

24 de Greiff, "Introduction," 10-11. 
impunity. If the aim of a reparations program is to reassert the status of victims as equal citizens and rights holders, it is difficult to envision how this task can be achieved unless, at the same time and as part of the democratization process, structural reform measures are also undertaken to eradicate practices and transform institutions expressing women's subordinate status as secondclass citizens. Thus, depending on the country at stake, ensuring the external coherence of a reparations program with the aim of reasserting women's and girls' equal citizenship status may be an essential but daunting task involving major legal and institutional reforms - reforms that obviously call for more interactions between victims' and women's groups (among others) than has been the norm in most transitions. ${ }^{25}$

The category of "finality" refers to whether receiving benefits from a program forecloses other avenues of civil redress. ${ }^{26}$ Though there may be both advantages and disadvantages to rendering a program final, all I would like to add here is that if a program is made final in this sense, it can apply only to violations for which there has been reparations instead of referring, more generically, to past abuses. This will ensure that in the case of those reparations programs that systematically fail to include the worst forms of violence and abuse perpetrated and tolerated against women as "repairable crimes," the judicial path remains open. A sequence of successful cases may act as a trigger to motivate the state to undertake new programmatic reparations initiatives to ensure, at least over time, the comprehensiveness of its reparations policy. Hence, the importance of circumscribing carefully the reach of a program's finality.

The "munificence" of a reparations program relates to the magnitude of its benefits from the individual beneficiary's perspective. ${ }^{27}$ Because so much of what has been said thus far would seem to indicate that "engendering reparations" will require multiplying the number of potential beneficiaries (mostly by enhancing the completeness and comprehensiveness of the program), it is worth thinking about how to respond to the likely criticism that this will either increase the costs of reparations (and maybe make governments more resistant to the idea of reparations) or reduce the amounts distributed to each beneficiary to such an extent that reparations become meaningless in practice. There are several concrete options for policymakers to explore here. These include, when talking about individual payments, the option of apportioning them among different family members, but also thinking about ways of distribution (of the same amounts) that may ensure that they reach women better (for instance, small pensions versus large one-time lump-sum payments). A possibility

\footnotetext{
25 Rubio-Marín, "Introduction."

${ }^{26}$ de Greiff, "Introduction," 12.

27 Ibid., 12-13.
} 
explored in Timor-Leste and Sierra Leone includes prioritizing, when it comes to monetary reparations, the most vulnerable victims (something that is likely to have a positive impact on women).$^{28}$ More importantly, the complexity of a reparations program that combines small individual payments with other types of benefits (services, symbolic, collective) to ensure that reparations are truly meaningful to victims may be just as successful. After all, past experiences show that the complexity (especially a combination of material and symbolic) and the coherence (especially the delivering of reparations together with truth and/or justice) of a reparations program may be more important in determining victims' satisfaction than its overall munificence.

Although de Greiff ends his taxonomy here, I would like to propose adding two further categories for the assessment of reparations programs. The first one can be called "openness" and refers to the level of participation of victims, victims' groups, and other relevant actors in civil society in the design of a reparations program. There are both instrumental and intrinsic reasons to commend the openness of a reparations program. The main idea is that victims' adequate participation in the process can not only provide information needed for the proper design of programs, but can also, in itself, have a reparative effect by affirming the victims' status as active citizens buttressed by the state's willingness to engage with them as valid interlocutors. ${ }^{29}$ Although this effect may obtain generally, regardless of the type of victim, it may be particularly important for sectors of the population that have been systematically marginalized and not only episodically oppressed. This usually includes women, but it also includes, depending on the case, other marginalized groups such as indigenous groups and other oppressed minorities.

In this regard, there is a promising trend. Until recently, women's groups have not been particularly engaged in discussing reparations. Rather, such discussions tended to be exclusively left to victims' groups and human rights groups. Thus, women's participation tended to be mostly conducted either through their involvement in victims' groups (in which they often participate as family members of the disappeared or killed) or through specific associations representing some partial interest (such as widows' associations, or associations focusing on the displaced). This is now changing. Indeed, in more recent reparations discussions, such as those that took place in Sierra Leone ${ }^{30}$ and those now taking place in Colombia, there is some involvement of groups representing women's rights more broadly. This can have the important effect

\footnotetext{
${ }^{28}$ See Wandita, Campbell-Nelson, and Pereira, and Jamesina King, "Gender and Reparations in Sierra Leone: The Wounds of War Remain Open," in What Happened, 246-283.

${ }^{29}$ See Rubio-Marín and de Greiff, "Women and Reparations."

$3^{\circ}$ See King.
} 
of incorporating the views of victims of sexual violence who in many contexts and for obvious reasons are unlikely to organize and mobilize publicly as such. More generally, conceived as a space for the participation of victims, the design and implementation of an administrative reparations program can, in itself, be a project that offers women a reparative sense of recognition both as victims and as valuable agents of political and social transformation.

Finally, by "transformative potential" I mean the extent to which a reparations program has the capacity to subvert, instead of reinforce, preexisting structural inequalities. Although our concern here is with gender hierarchies of power, this concept may apply to other forms of structural inequalities. The challenge that this category responds to is that of understanding how a reparations project, whose aim is to give victims recognition as equal rights holders, can address the fact that some groups were not equal rights holders before the violent or authoritarian episode that triggered their access to the reparations benefits. This said, we must bear in mind that reparations can at best bring about very modest transformations, and that larger transformations will have to come from broader structural and legal reforms that ought to accompany the democratization process. Still, because of their symbolic meaning and the need for internal and external coherence, reparations programs should not miss out on whatever opportunities there are to contribute to the transformation. To illustrate, reparations programs need not conform to or contribute to the entrenchment of preexisting patterns of female land tenure, education, or employment. They may also challenge gender-biased inheritance rules. This was the case, for instance, in Morocco, where the recent Equity and Reconciliation Commission (2002-2003), departing from the prior precedent set by the Arbitration Commission (1999), decided to apportion benefits among family members of the deceased victims in a way that departs from the sharia-based law of inheritance, giving a larger share of those benefits to women $(40 \%$ as opposed to $1 / 8$ or $12.5 \%$ ) rather than to the eldest son. Also, and as Bernstein's chapter in this volume shows, there is space to think about what modalities of reparation (including shares in microfinance institutions, education, and vocational training) can help women move beyond the baseline they departed from and help them achieve greater autonomy and independence during the reconstruction. Ideally, then, the process of designing a reparations program should provide an opportunity to discuss what it takes for a democratic regime to be truly inclusive of women. 